\title{
Una teología de ojos abiertos Teología y justicia. Perspectivas
}

\author{
F. Javier Vitoria Cormenzana \\ Instituto Diocesano de Teología y Pastoral, Bilbao \\ Centro de Reflexión Teológica, San Salvador
}

\section{1. ¿Tiene futuro el cristianismo mesiánico?}

¿Cuáles son las perspectivas de la relación entre teología y justicia o entre fe y justicia? No me ha resultado nada sencillo articular una respuesta a esta cuestión que no sea producto de un voluntarismo a prueba de cualquier análisis. Mi primera impresión me decía que el futuro del binomio fe y justicia, tanto en su versión biográfica como reflexiva, no era muy halagüeño. El brillante análisis que acaba de hacer Chema Mardones' no ha hecho más que confirmar mi sospecha. Digámoslo sin rodeos: no parece que esta teología y el cristianismo que la hace posible tengan ante sí un camino franco. Ni la sociedad neoconservadora y posmoderna española, ni la dirección de la marcha de nuestra Iglesia se lo van a poner fácil. Culturalmente, asistimos al final de la plausibilidad social del cristianismo mesiánico, y eclesialmente, muchas señales parecen indicar que nos encaminamos hacia el ghetro.

En los últimos años, en los ambientes teológicos, se ha repetido hasta la saciedad una pregunta: ¿qué queda de la teología de la liberación? Las respuestas

1. Este escrito recoge una intervención oral que el 4 de abril realicé en Madrid, en un curso organizado por la Cátedra de Teología Contemporánea del C. M. U. Chaminade, patrocinada por la Fundación Santa Maŕa. Ese dra, comparts tiempo y espacio con mi buen amigo Chema Mardones. Ni él ni yo sabíamos que sería por última vez. El dla 23 de junio, Chema falleció súbitamente, en su domicilio. No es éste el lugar para glosar su rigor intelectual y su exquisita sensibilidad cristiana, que le convirtieron en un testigo privilegiado de las transformaciones socioculturales de nuestro tiempo y de sus repercusiones en el cristianismo. Pero sí quiero dejar constancia de que, en los años 70, y en Bilbao, juntamente con un grupo de compañeros y amigos, hizo posible una 
de unos y otros no se han hecho esperar. A veces, escuchándolas, he tenido la impresión de que estaba asistiendo a una contienda, más virtual que real, entre dos posiciones irreducibles. Sus detractores de siempre proclamaban a bombo y platillo su final, como consecuencia del desmoronamiento del socialismo real. Muchas veces, sus partidarios hemos dado la impresión de participar en una operación rescate de los restos de un naufragio. Interrogantes parecidos se podrían haber dirigido a la teología política europea. En cualquier caso, sea cual sea nuestra particular percepción de sus respectivos futuros, parece innegable que estamos asistiendo al final de una generación de eminentes teólogos que, desde diversas sensibilidades culturales, sociales y políticas, concibieron la causa de la justicia en el mundo como el desafío mayor a su esfuerzo por pensar la fe. Sus nombres están en la mente de todos: G. Gutiérrez, J. Sobrino, L. Boff, J. Moltmann, J. B. Metz, J. I. González Faus, J. Lois, J. Mª Castillo, y un largo etcétera. El presente no trae consigo buenos pronósticos para su herencia.

¿Y el futuro? Dependerá, en gran medida, de la existencia de comunidades, grupos e instituciones cristianas que, incorporados a la corriente vital del concilio Vaticano II, hagan de la alianza de la fe con la justicia su seña de identidad. Así ha ocurrido hasta nuestros días. La teología, como explica la conocida fórmula de G. Gutiérrez, es un hablar (discurso segundo), enriquecido por el callar de la práctica cristiana (que es el verdadero discurso primero).

Y ente paréntesis, digamos que no conviene olvidar el carácter minoritario de los grupos y movimientos eclesiales que practicaron un cristianismo mesiánico, en los años de 1970 y 1980 del siglo pasado. Una cosa es que reconozcamos su trascendencia social y eclesial de entonces; $y$ otra muy diferente que, al lamentar su desvaída significación actual, dejemos flotando en el aire la idea de que la mayor parte del catolicismo social posconciliar era de índole mesiánica. De hecho, su configuración de ayer más bien correspondía, como la del catolicismo de hoy, a una religión para las festividades burguesas.

El nuevo paradigma cultural de la modernidad le había planteado un vital desafío hermenéutico a la Iglesia: la reinterpretación crítica de su pretensión salvífica. El Vaticano II deja tras sí siglo y medio de lamentable historia de desencuentros y resistencias. Y -ipor fin! - la Iglesia hizo suyo el envite y emprendió la búsqueda de lugares de contacto para la decisión de la fe, en la experiencia humana contemporánea. Solamente si da con propuestas adecuadas, evitará que se desestimen las razones y motivos para creer que ella ofrece a los hombres y mujeres con los que convive. Entre esos lugares de experiencia destaca aquel que propone la expectativa de la justicia como lugar para el encuentro con la fe.

convocatoria laical, cuya seña de identidad la constitúa la alianza fe y justicia. Entonces, su compromiso acreditó entre nosotros el cristianismo mesiánico. Hoy. esperamos que su muerte sea fecunda para el futuro de esa alianza. 
Tanto la teología política europea como la(s) teología(s) de la liberación responden a esta perspectiva.

El concilio situó el tema de la justicia en estrecha referencia con la fe y la tarea evangelizadora de la Iglesia, aunque no abordase de un modo expreso sus relaciones. El descubrimiento de los pobres fue algo así como la luz matinal del Espíritu, que ilumina el camino posconciliar y que termina en la vinculación definitiva de la fe y la justicia. Merece la pena recordar un par de intervenciones proféticas, realizadas en el contexto conciliar. Justamente, un mes antes del comienzo de las sesiones conciliares, Juan XXIII plantea por sorpresa el tema de la Iglesia de los pobres: "Frente a los países subdesarrollados la Iglesia se presenta tal y como es, y quiere ser la Iglesia de todos y, particularmente, la Iglesia de los pobres". En el aula conciliar y durante el debate de la primera sesión, el cardenal Lercaro hará la siguiente intervención: "No daremos satisfacción a las exigencias más auténticas y profundas de nuestra época, no responderemos a la esperanza de una unidad compartida por todos los cristianos, si hacemos del tema de la evangelización de los pobres uno de los muy numerosos temas del concilio. No se trata efectivamente de un tema cualquiera; se trata, por decirlo así, del tema de nuestro concilio. $\mathrm{Si}$, tal como se ha dicho aquí mismo varias veces, es exacto afirmar que la finalidad del concilio estriba en hacer a la Iglesia más conforme con la verdad del Evangelio y más apta para responder a los problemas de nuestra época, podemos decir que el tema central de este concilio es la Iglesia, precisamente en cuanto es la Iglesia de los pobres".

Tras el concilio la alianza fe-justicia se va convirtiendo en una cuestión prioritaria, en algunos ámbitos de la Iglesia. En el año 1971, el documento final del III Sínodo ordinario de obispos sobre La justicia en el mundo, va a situar el tema de la lucha por la justicia en clave de misión evangelizadora: "La acción en favor de la justicia y la participación en la transformación del mundo se nos presenta claramente como una dimensión constitutiva de la predicación del Evangelio, es decir, la misión de la Iglesia para la redención del género humano y la liberación de toda situación opresiva"2.

De esta manera, se da un paso decisivo al establecer, de modo expreso, la relación entre lucha por la justicia y anuncio del evangelio. Algunas órdenes religiosas, como la Compañía de Jesús, juzgaron que la promoción de la justicia constituía una exigencia absoluta del servicio de la fe, en cuanto formaba parte de la reconciliación de los hombres, exigida por la reconciliación de ellos mismos con Dios. Muchos cristianos la consideraron como la prueba crucial para la validación histórica de la acción evangelizadora de la Iglesia. Y se comprome-

2. Cfr. III Sínodo Ordinario de Obispos, La jusficia en el mundo, en Ecclesia 1572 (1971) 2295-2302; el texto citado, en 2295. 
tieron en movimientos de liberación o de transformación social, tanto en América Latina como en Europa.

En España, el final del régimen autoritario del general Franco fue el caldo de cultivo sociopolítico, donde brota y se afianza el cristianismo mesiánico, que va a adquirir una especial relevancia, en el proceso de transición democrática. Hoy tanto el contexto social como eclesial han cambiado muchísimo. Pero el teólogo, cuando encara el futuro [también el de la teología política], no puede contentarse con reflexionar sobre los resultados de los análisis y diagnósticos socioculturales, aunque sus datos le resulten imprescindibles.

\section{Vivir y hacer teología coram Deo}

Para titular mi intervención de esta noche he utilizado una fómula, "una teología de ojos abiertos", que prolonga otra, "la mística de ojos abiertos", de J. B. Metz. Recurro a ella por dos motivos. En primer lugar, busco reivindicar un modo de pensar la fe, lúcido con los padecimientos terrenos de este tiempo, en el que, según Pedro Casaldáliga, existen demasiados téblogos que, cuando hablan o escriben, parece como si ya estuvieran definitivamente instalados en el cielo.

En segundo lugar, pretendo defender la vigencia y la urgencia del cristianismo mesiánico y de su perspectiva teológica, a pesar de su irrelevancia cultural y eclesial. También hoy, la teología cristiana posee potencialmente una agudeza visual especial para percibir las injusticias de nuestro mundo globalizado y desenmascarar las ideologías que las encubren con el fin de liberarlo del poder de los ídolos. Me refiero a una competencia cognitiva, sustentada en la tradición religiosa judeocristiana, que nadie puede asegurar "desde fuera" con independencia de su generación, conservación y reactualización históricas. Esta capacidad está todavía hoy viva, en bastantes comunidades, grupos e instituciones eclesiales. Todos ellos, memoria viva de las tradiciones proféticas, comparten sin vacilar una visión teológica sobre nuestro mundo, que muy bien puede expresarse con aquellas palabras que una mirada incisiva sobre Sudafrica provocó en Albert Nolan: "Dios está airado. Dios está literalmente furioso por lo que se está haciendo hoy". Todos ellos, viviendo y pensando coram Deo, perciben la ideología neoliberal del mercado capitalista no sólo como una ideología, sino como expresión de un orden social idolátrico, que exige sacrificios humanos y la muerte del Dios de Jesús de Nazaret para entronizar a su dios ${ }^{3}$.

Es cierto, se trata de una competencia que hoy está muy amenazada, que puede perderse, y en la que, seguramente hoy más que nunca, los cristianos debemos ser iniciados y educados, y mantenerse en la cual exige el esfuerzo permanente

3. Cfr. J. A. Zamora, "Neoliberalismo y teodicea. Sobre los intrincados caminos de la razón apologética moderna", Scripta Fulgentina 15-16 (1998) 223. 
de la conversión". Pero el "Dios airado y furioso" con el mundo que estamos construyendo no va a cejar en su empeño de ser Luz para nuestros ojos cegados por "las cataratas" culturales de la inocencia y la indiferencia. La presencia del Espíritu de Dios en la historia humana, actuando como su "Aguijón y Caricia a la vez", es el mejor estímulo y garantía - ¡divino! - del futuro de un cristianismo de la fe y la justicia. Para percibir su urgencia y actualidad, nos bastará con dejamos penetrar por la mirada del Dios de Vida, que se refleja en los ojos de las víctimas del orden mundial, mientras contemplamos la sociedad en la cual vivimos y la Iglesia en la cual profesamos la fe. De su capacidad para convertir eficientemente en historia la oferta cristiana de salvación, en el interior de los infiemos de nuestro mundo, dependerá su relevancia para los seres humanos sacrificados en ellos. El veredicto sobre su relevancia o su insignificancia lo dictarán los integrantes de la ekumene de las víctimas, según el paradigma de Mateo 25,31 ss, y no los integrantes de los insonorizados y apáticos areópagos modemos.

\section{Vivir y hacer teología bajo la autoridad de las víctimas}

Sinceramente, no me parece ajustado afirmar que la teología es una de las variantes más brillantes de la literatura fantástica. La mejor de sus versiones no se nutre en viajes fantásticos al país de las maravillas donde se celebra "el-nocumpleaños" o al no menos fabuloso "país de Nunca jamás", donde viven felices los nin̄os que renunciaron a crecer. Al contrario, paradójicamente y desmintiendo el sentido etimologico de la palabra ${ }^{5}$, se alimenta de una mística de ojos abiertos (J. B. Metz) que dilata, como si de un colirio se tratase, las pupilas de los ojos del teólogo para ver y comprender el sentido de la historia (Ap 3, 18).

Su secreto consiste en la pretensión de servir a Dios, en el enorme dolor del mundo. El cristianismo originario de Jesús de Nazaret recuerda permanentemente la autoridad de los que sufren, de las víctimas de la historia. El cristianismo comenzó su andadura histórica como recuerdo y seguimiento de alguien que miró de frente el sufrimiento del otro. La primera mirada del judío Jesús no fue sobre el pecado de los seres humanos, ni sobre la identidad cultural o pertenencia comunitaria, sino sobre las existencias humanas rotas por el sufrimiento. El secreto de la mistica cristiana de la misericordia, de aquella que gratuitamente

4. Aunque sea en nota, quisiera dejar constancia de algo que considero de una importancia mayor. Seguramente, una de las lecciones que nos deja el pasado es que fuimos muy poco cuidadosos con la mistagogla, que introduce en la experiencia evangélica de la fe y la justicia. No deseamos abisalmente, ni buscamos suficientemente el manantial espiritual del que brotan sus exigencias, haciéndolas practicables. Y quemamos demasiadas energlas vitales y demasiados efectivos para la causa, por no haber aprendido a paladear el gozo del hallazgo y del encuentro.

5. La palabra mystikos proviene del verbo griego myo que significa cerrar. 
pretende llegar a Dios, sin dejar al margen el enorme dolor del mundo, consiste en unir indivise et inconfuse dos binomios: mística-gratuidad y política-justicia.

- Como télogo profesional, siempre he querido tener presente aquella impertinencia de S. Kierkegaard: "¿Qué es un profesor de teología? Es alguien que es profesor, porque otro ha sido crucificado".

El desafío histórico que la injusticia plantea al cristianismo sólo encuentra respuesta en un ejercicio de fe, que convierta la lucha o promoción de la justicia, en un integrante imprescindible del corresponder creyentemente a Dios. La propuesta de un cristianismo, sensible al clamor y dolor de las víctimas de la historia, privilegia la periferia y la frontera como elementos constitutivos de su identidad y como lugares de su presencia misionera. Por eso mismo, como el Siervo de la Justicia de Dios, "acampa" en los territorios habitados por los seres humanos ninguneados, sistemáticamente empobrecidos y tratados como excedentes humanos, para ofrecer y desplegar allí todo el potencial de compasion, reconocimiento y universalización que atesora su tradición. Su morada la construye en ese laberinto de parajes diabólicos, donde la humanidad corre riesgos crecientes. Allí hace ofr su voz profética con el fin de sacudir la inercia y la apatía de la cultura dominante y propone, creativa e imaginativamente, nuevas experiencias de humanización. Incesantemente, recorre una interminable franja de terreno, que le conduce hacia el exterior, hacia los extraños, hacia el mundo "extranjero", hacia "los gentiles" de este tiempo de globalizaciones injustas, y tiende puentes para que, dando y recibiendo al modo del Dios trinitario, se produzca el encuentro fraterno y amistoso con ellos. Los intereses y compromisos de esta fe se asemejan más a los del Dios de Jesús, en la medida en que se crece en sensibilidad hacia el sufrimiento del inocente.

Hay una justicia nueva que brota de esta fe. Su vivencia anroja luz sobre la praxis de la justicia y ayuda a percibir aspectos falsificados, ignorados o encubiertos, por la mediocridad de los sentimientos y la pedantería de las argucias racionalistas. Cuando se pregona el triunfo del capitalismo democrático, la vivencia de la fe hace sentir con nuevos bríos la cuestión de la justicia como la búsqueda incesante de una justicia siempre mayor. La visión creyente de las víctimas del actual culto idolátrico se alza como reparo ante toda representación histórica de la justicia. La fe ocasiona y anima proyectos liberadores, encaminados a que la historia dé más de sí en la dirección de una justicia siempre mayor. Nada hay de titánico en este empeño por "apurar" la historia. El cristianismo no lo percibe como exigencia de una nueva ley. Es su respuesta a la gratuita y todavía inédita promesa de Dios, posibilitada históricamente por Jesucristo.

En el siglo XXI, esta práctica de Dios será la mejor expresión de su identidad evangélica, dentro de su siempre mayor inadecuación; y la más adecuada salvaguarda de su relevancia también en sociedades agnósticas y secularizadas como la española. El cristianismo está llamado por la fe, y no solamente por 
razones éticas y políticas, a alzar su voz condenatoria contra la barbarie del actual orden internacional y a ponerse, efectivamente, al servicio de un Nuevo Orden Internacional (con mayúsculas). A la vista de lo que sucede en nuestro mundo globalizado, no parece suficiente la llamada del magisterio eclesial acerca de la necesidad de la fe en la existencia de Dios para la construcción de un orden social y político justo, coherente con "la civilización del amor". El cristianismo necesita "salvar o redimir a Dios" de su insignificancia y de su deshonor en la historia. Un autor de la Cábala hace decir a Dios, dirigiéndose a sus fieles: "Si ustedes dan testimonio de mí, yo seré Dios; de lo contrario, no". En lo tocante a la salvación de las víctimas del orden mundial, todo sucede como si Dios hubiera renunciado a "su responsabilidad", para confiarle la empresa a los seres humanos. En ese anonadamiento divino, la gloria de Dios queda en manos de los hombres. "Una vez que se ha entregado por completo al mundo y a su devenir-escribirá H. Jonas - , Dios ya no tiene nada que dar. Ahora le toca al ser humano darle lo suyo a Dios". Y "lo suyo", lo propiamente de Dios, es la vida y la dignidad de las víctimas de nuestra barbarie. El cristianismo mesiánico del futuro bien pudiera adoptar, como Etty Hillesum, el principio de "ayudar a Dios tanto como sea posible", ahora que toda la superficie de la tierra, como profetizara la víctima del extermino nazi, no es más que un inmenso campo de concentración, y nadie, o casi nadie, puede quedar fuera de él. A Dios se le "ayuda" con la compasión y la justicia, unidas de manera indivisible e inconfundible. La Iglesia actual, tan diestra en canonizar y festejar a hombres y mujeres que vivieron por la compasión, debiera asumir como suyo propio el destino histórico que les suele esperar a los que viven por la justicia: ser crucificados.

\section{Vivir y hacer teología, concernidos por la cuestión de la teodicea}

Tiene razón J. B. Metz cuando afirma que la teología cristiana ha intentado desde un principio suavizar o paralizar la cuestión de la justicia para los que sufren sin culpa, mediante la transformación de este problema, en la cuestión de la salvación de los culpables. Con ello, la doctrina sobre la salvación, la soteriología, sustituía o hacía innecesaria la teodice ${ }^{6}$.

$Y$, sin embargo, la negación del derecho y la justicia entre los hombres atenta directamente al contenido del credo cristiano, en cuanto parece desmentir esa soberanía de Dios que, como Misericordia Fiel, se ha ido haciendo historia de nuestra historia y came de nuestra came, en el envío del Hijo-Jesucristo y de su Espíritu. Un acontecimiento justiciero y liberador se encuentra en el centro de la fe veterotestamentaria ( $c f r .$. Ex 3, 7-10), y la cercanfa de Dios como justicia para los pobres y humanización para los hombres, en la neotestamentaria ( $c f r$. Mc 1, 15). La fe cristiana tiene su origen en la experiencia de que la Salvación de Dios,

6. J. B. Metz, Un hablar de Dios sensible a la seodicea, en Id. (dir.), El clamor de la fierra. El problema dramb́tico de la Teodicea, Estella, 1996, p. 63. 
realizada por y en Jesucristo ( $c f r$. Rom 4, 25; Col 1, 19-20), ya está operando en la historia, aunque no nazca ni se agote en ella. La flagrante injusticia del mundo - y sus víctimas constituyen el gran obstáculo para esta fe, la aniquilación de la idea de presencia liberadora de Dios entre los hombres. Los diversos panoramas de la injusticia, las víctimas de la pobreza, el mapa de los derechos humanos, la degradación del medio ambiente, las agresiones a las minorías culturales, la discriminación de género, los atentados a la paz, etc., impiden que la Iglesia pueda pretender un anuncio sincero de esta salvación, dando la espalda a esta realidad o, como dijera I. Ellacurla, "echando sobre ella un manto que cubra sus vergüenzas".

La experiencia de la noche oscura de la injusticia ha purificado la fe de la Iglesia. La pregunta que brota desde ese lugar infernal ha sido recogida por la teología europea, en una fórmula ya emblemática, "¿cómo hablar de Dios después de Auschwitz?". La latinoamericana de la liberación la ha actualizado perturbadoramente: “¿cómo hablar de Dios durante Ayacucho?". Hoy, las preguntas sobre la localización de Dios se siguen multiplicando incesantemente. Eso si, entrecortadas por los gritos y lamentos de los hombres y mujeres que son exterminados en tantos escenarios de muerte como pueblan contemporáneamente la geografía mundial.

La perspectiva de la justicia mueve al esclarecimiento de la pregunta humana sobre dónde está Dios, a partir de la respuesta práctica al interrogante divino, “ ¿dónde está tu hermano?" (Gen 4, 9). Así, ha rescatado a Dios de su secular confinamiento, en una transcendencia abstracta. La pregunta teológica capital ya no versa acerca de la existencia de Dios, sino de qué Dios es el que existe, de cómo se hace él presente en la vida y actúa en nuestra historia y de cómo podemos conocerlo y reconocerlo. Todo ello le ha pernitido barmuntar algo de lo que significa que Dios sea un Dios de Vida.

\section{Vivir y hacer teología enfrentados a los ídolos}

"Aunque sonrían las estadísticas, se jode la gente". El año 1970, Eduardo Galeano escribió estas sabias y provocativas palabras, que apostillo con estas otras: "en sistemas organizados al revés, cuando crece la economfa también crece, con ella, la injusticia social"". Se referían a la situación de América Latina, pero podian hacerse extensivas a otras partes del planeta mundo. Entonces bastaba con estar medianamente despierto para compartirlas. Transcurridos treinta y seis años, aunque la lectura de los informes del Programa de Naciones Unidas para el Desartollo sobre este mundo globalizado patas arriba da grima, una pandemia de ceguera, de la que alertan el evangelista Juan y José Saramago, impide ver que la inmensa mayorfa de la humanidad no tiene más que "el derecho de ver, oír y callar"s, mientras le llega la temprana hora de una muerte injusta.

7. Las venas abiertas de América Latina, Madrid 1994, p. 464

8. E. Galeano, Patas arriba. La escuela del Mundo al revés, Madrid, 1998, pp. 342-343. 
Se puede convenir con el escritor uruguayo que en todos estos años, mientras la pobreza iba aumentando paulatinamente, se perdía una cierta unanimidad universal, en torno a algunas cosas elementales. Entonces, la pobreza era resultado de la injusticia. Lo proclamaba la izquierda, el centro lo admitía y la derecha no lo discutía. Había pobreza, porque había injusticia, un reparto injusto de los panes y de los peces. Hoy, ya quedan muy poquitos que digan que la pobreza es resultado de la injusticia. Hasta en la izquierda ha prosperado esa especie de dogma de fin del siglo XX y comienzos del siglo XXI, según el cual la pobreza es el castigo que la ineficiencia merece $y$, por lo tanto, no es el resultado de la injusticia, sino un acto de justicia: "se jode el que no trabaja o el que no sabe defenderse y el que no sabe competir y el que no es eficiente ni rentable".

La situación mundial, en estos inicios del siglo XXI, da muestras sobradas de la ambigiuedad y los agujeros negros del orden internacional, de su carácter de conquista así como la ideología encubridora que lo acompaña. Desde la perspectiva de la religión cristiana, conviene destacar muy especialmente su impostura idolátrica y su violencia sacrificial. En su interior, la mayoría de la población mundial desempeña el papel de chivo emisario, que permite el bienestar de la minoría, que vive en la opulencia. Las víctimas no solamente son los ya muertos y los seres espectrales, postrados "en parajes de sombras de muerte", sino también los aún no nacidos por encontrarse, desde siempre, obligados a morar en esos mismo lugares. La exclusión y segregación de más de dos mil quinientos millones de seres humanos, por causa del hambre, del sida, de las guerras, del desempleo, del mercado único y extorsionador que se pretende libre, nos recuerda que somos parte de una cultura parricida, filicida y fratricida, donde la sangre del otro es dada a pérdida.

El desatino mayor del orden id6latra que se nos impone consiste en querer organizar la sociedad mundial etsi pauperes non darentur, sin percatarse de que extra pauperes nulla salus. Vincular el futuro de la humanidad al destino de los pobres se ha hecho una necesidad histórica, que "la deriva totalitaria" del liberalismo no quiere reconocer. Solamente las víctimas pueden redimirlo. De su mirada brota, nuevamente, la exigencia y la tarea de "pasarle el cepillo a contrapelo" (W. Benjamin) al nuevo orden mundial para confrontarlo con la utopfa de la familia humana.

A pesar de que los acontecimientos terroristas de septiembre de 2001 y las reacciones posteriores de todo tipo pusieron nuevamente sobre el tapete de la actualidad el uso instrumental de la religión y la "lucha de dioses" (J. Saramago), que se habla establecido en todo ello, podemos reivindicar la función socialmente saludable de la religión para organizar un mundo fraterno y solidario, libre y justo. La religión entendida - ¡claro está! - como "el inextinguible impulso, sostenido contra la realidad, de que ésta debe cambiar, que se rompa la maldición y se abra paso la justicia" (M. Horkheimer). 
El orden internacional es un desafío permanente a la tradición cristiana. Su propia condición mesiánica está en juego. Ni las tremendas y diabólicas tergiver- saciones que los seres humanos hemos cometido como "constructores de nueva humanidad" deben llevarnos a la renuncia de la condición mesiánica del cristianismo o a una lectura a la baja de la ilusión de ser hombres y mujeres nuevos, creadores de la historia. El cristianismo tiene mucho de mística para un combate en favor de un orden mundial solidario. Las iglesias y el cristianismo no tienen en sus manos la solución al desorden intemacional imperante. Sin embargo, son portadores de un impulso espiritual, nacido de su confianza en que las posibilidades inéditas e inauditas del Dios de Jesús son viables, en la historia. Esta convicción origina resistencias a ser cómplices del espíritu del tiempo -más concretamente, de su capitulación ante la lógica férrea del presente-, y sueños emancipatorios que fuerzan a ir siempre más allá y a sobrepasar el sistema mundial vigente, sustituyéndolo por otro, que haga factible la vida de sus víctimas.

La fe cristiana se niega a aceptar que la lógica de los sirvientes de los ídolos sea la que tiene la razón. El cristianismo mesiánico, revestido de las armas de Dios, se dispone a combatir contra los principados, contra las potestades, contra los dominadores de este mundo tenebroso, contra los espíritus del mal, que están en el aire (Ef 6, 10-20). Con las armas de Dios, este cristianismo estará dispuesto a introducirse en las intrincadas condiciones de nuestro mundo para transformarlo, en favor de la justicia y la vida.

\section{Vivir y hacer teología como seguidores y discípulas de Jesús de Nazaret}

Toda esta persuasión, que vincula de manera indisoluble la fe y la justicia, encuentra su arraigo radical, primeramente en la fe de Jesús de Nazaret y, tras la pascua, en la de sus discípulos. Ambas ligaron de modo originario e indisoluble el destino personal de Jesús a la esperanza mesiánica. La experiencia teologal de Jesús arraigó y ahondó en la tradición judía. El Dios de Israel no era uno entre muchos, ni siquiera uno sobre muchos dioses. Él era el único Dios verdadero de toda la tierra y de todas las naciones, porque sólo Él era un Dios de justicia y derecho para los sistemáticamente vulnerables y segregados de la sociedad: los desvalidos, los huérfanos, los indigentes y los necesitados. Yahvé se levanta contra la injusticia y la maldad, porque así son su naturaleza y su carácter. Los dioses de las otras naciones son falsos (es decir, ídolos), porque han fallado a los desdichados de la tierra.

Prosiguiendo esta tradición, en la actividad de Jesús de Nazaret, Dios Padre aparece como el enemigo de las fuerzas diab6licas y de los ídolos de muerte. El Dios del reino adviene a una historia, en la que las fuerzas negativas de la creación (los dinamismos diabólicos, representados por el Maligno) y el pecado tienen poder. Su irrupción en la historia supone contradiccion y conflicto con la realidad presente. Las acciones de Jesús, sus milagros y curaciones, constituyeron 
auténticas interrupciones del circuito del mal, que avasalla la vida de los hombres y, muy singularmente, de los pobres y de los débiles. En Jesús de Nazaret, el Padre del reino y Dios de la Vida emprenderá su lucha contra el Maligno y contra los ídolos de muerte, representados por Mammón. Entre el $A b b a$ del reino y Mammón (Mt 6, 24) existe una antinomia irreconciliable. Todo el que está aliado con Mammón está excluido de la familiaridad con el Padre del reino, porque "nadie puede servir a dos señores". La antinomia Abba-Mammón se actualiza históricamente dentro de la alianza de Dios con los pobres o de la parcialidad de Dios por las víctimas del (des)orden mundial. Como ha repetido en multitud de ocasiones A. Pieris, el Padre de reino asume la lucha de los pobres contra los ídolos de muerte como propia, de modo que se convierte en la lucha divina por la vida de los pobres, la lucha emprendida por el Dios del reino contra los orgullosos, los poderosos y los ricos (Lc 1, 51-53).

La fe cristiana, que renace de la práctica de la justicia, confiesa a Dios, Amor creador, Padre fiel y misericordioso ( $c f r$. Os 1, 6-9; 2, 1-3), defensor de los pobres y de los oprimidos ( $c f$. Sal 82; 145, 10), que ha acampado en medio de los hombres, para hacerles participar de la plenitud de su vida (cfr. In 1, 14). La fe mesiánica confiesa a Jesús de Nazaret como plena y definitiva presencia de Dios, en esta historia humana, como manifestación máxima de la solidaridad y de la comunicación de Dios con todos los seres humanos y como la suprema expresión de la vigencia de la promesa divina para los pobres. El cristianismo más original proclamó que la crucifixión de Jesús, bajo el poder de un orden social y religioso, que exigía y producía víctimas humanas, era la suprema manifestación histórica de la solidaridad de Dios con los hombres. Loca e insensatamente, Dios se revelaba no sólo en su misericordia fiel hacia los pobres, sino también en sus padecimientos con ellos, como ellos y en ellos; no sólo como garante de la causa de las víctimas, sino también como participante de su destino histórico. Esta fe confiesa asimismo que la resurrección de Jesús por la fuerza del Espíritu del Padre es la prueba suprema de que Jesús era de Dios y estaba con Dios; y de que la gloria divina consiste en recuperar lo que se ha perdido definitivamente, a causa de los egoísmos criminales de los hombres.

La memoria cristiana recuerda permanentemente que Jesús de Nazaret fue derrotado por la fuerza violenta del orden del imperio. Acusado de un delito contra la pax romana, fue ejecutado en la cruz, un suplicio propio de extranjeros hostiles, y su sangre fue dada por bien perdida, por los representantes del orden establecido. Sin embargo, la memoria cristiana confiesa que el Crucificado es el Mesías de los pobres ( $L$ c 4, 16-20), la Víctima, el heredero del trono de David (Lc 1, 33), el Siervo sufriente, el Hijo de Dios (Heb 5, 7-9). El "Cordero degollado" había recibido en su resurrección toda la gloria destinada al mismo Dios (Ap 5,12 ss.). Desde entonces, la gloria del Hijo de Dios no admite ser separada de la vergüenza de su cruz (Fp 2,5-11), ni su condición filial del hermanamiento con las víctimas de la historia. 
Tras su triunfo sobre la miseria de nuestra condición humana y de nuestra injusta inhumanidad, Jesús, el Hijo entregado, sigue ligado fraternalmente, por - medio de su Espíritu, a todos los seres humanos. Según afirma el concilio Vaticano II, "el Hijo de Dios, por su Encarnación, se unió de alguna manera con todos los hombres" (GS 22). Pero en los inicios del siglo XXI, esta solidaridad o atadura constitucional de la filiación de Jesús se establece en una historia en la que la mayor parte de la humanidad está obligada a una victimación permanente e injusta, en nombre de la "pax bushiana". El Hijo sigue siendo hoy partícipe de esta pasión humana. Así lo insinúa la parábola del juicio universal (Mt 25, 3145). Los hambrientos y los refugiados, los prisioneros torturados, las víctimas inocentes de la lógica de la guerra, que impera en nuestro mundo, los niños damnificados por los embargos comerciales o condenados a trabajar, a empuñar las armas o a prostituirse, etc., son hoy el cuerpo maltratado, escarnecido y crucificado del Hijo exaltado. Jesús, el Hijo Crucificado, funda su universalismo desde "los de abajo", la fraternidad universal entre los hombres, por su hermandad con los no-hombres. El Hijo resucitado es "esperanza para sí mismo", ya que, como Dios no es aún "todo en todas las cosas" (1Cor 15, 28). Él sigue "esperando desde entonces hasta que sus enemigos sean puestos por escabel de sus pies" (Heb 10,13). Él es para siempre el Emmanuel, el Dios que está con nosotros, envuelto en el acontecimiento agónico del mundo. También la Cabeza del Cuerpo padece y sufre cuando sus miembros padecen (1Cor 12,26$)$.

El seguimiento del Crucificado y la fe en el Resucitado hacen brotar una esperanza crucificada, que se opone tercamente a cualquier conato de interpretación optimista del progreso de la historia. Frecuentemente, las señales y las anticipaciones del futuro acaban intrahistóricamente en el fracaso y en la derrota. Pero, igualmente, esa esperanza es el mejor antídoto contra la tentación de abandonar la lucha contra los ídolos y en favor de una humanidad liberada y fratema. El cristianismo mesiánico motiva gratuitamente la permanencia en esta porfía. Solamente el amor a las víctimas de la injusticia y la confianza en la promesa de Dios justifican la fidelidad y la constancia hasta el final. Esta esperanza sustenta la convicción de que la injusticia y el mal no triunfarán definitivamente, a pesar de las incontables derrotas históricas de la causa de la justicia. El Espíritu, con obstinación divina, siempre vuelve hacer sentir su presencia actuante contra la servidumbre de la comupción a la cual es sometida la creación, y en favor de la gloriosa libertad de los hijos de Dios (Rom 8, 20). Cada derrota histórica se convierte, así, en el grano de trigo que da fruto al morir (Jn 12,24).

Esta esperanza enseña que la promesa de Dios no está medida por la capacidad de las esperanzas humanas, sino por su amor gratuito. Únicamente, gracias a su Espíritu, lo último y definitivo de la historia humana (el eschaton, que llamamos en jerga teológica), es decir, la Libertad, la Justicia y la Fraternidad (con mayúsculas), alcanzarán a todos los seres humanos, incluso a los vencidos y a los muertos. Más aún, la acción del Espíritu garantiza su presencia, en los avatares 
históricos. La esperanza mesiánica se configura como una confianza siempre abierta, en las posibilidades de la historia, que constantemente invita a explorar paciente y tenazmente, y explotar al máximo, el rico filón de lo todavía inédito, pero ya viable de la utopía de la familia humana universal.

El acompañamiento del Espíritu de Dios a la humanidad, su permanente y doloroso peregrinar por los lugares de muerte, su inhabitación en los corazones de hombres y mujeres de buena voluntad, su condición de alma y aliento de las comunidades cristianas, permiten dejarse encantar por el augurio de que esta historia, también en el siglo XXI, puede dar de sf algo diferente y altemativo o "revertirse", como I. Ellacuría reclamaba.

Termino donde he comenzado. El futuro de un pensamiento teologico concernido por la causa de la justicia dependerá de la existencia de biografías cristianas, individuales y colectivas, intempestivamente solícitas por una justicia siempre mayor y comprometidas con la causa de la vida de los seres humanos y, muy singularmente, de los pobres, que es la gloria de Dios. La memoria de la historia del cristianismo nos estimula a esperar - quizás, contra toda esperanza histórica- que el Espíritu suscite un cristianismo mesiánico también en las previsibles condiciones adversas del futuro. Lo integrarán hombres y mujeres aprendices junto a Dios de los secretos de la "economía del don" (P. Ricoeur), discípulos permanentes del "hombre supremo" - Jesús de Nazaret-, que se abaja hasta lo más profundo para dar vida, y habilitados por el Espíritu para una "entrega total" de la que sólo Dios es capaz (M. Horkheimer).

De nuestra propia historia mesiánica les legamos una dura y dolorosa lección, que quizás nosotros no hemos sabido asimilar todavía: la causa de la justicia no es fruto de ningún mesianismo prometeico y titánico, ni de voluntarismos heroicos, ni de la sola política, por necesaria que sea. La construcción de la historia, según las pautas divinas, requiere importantes dosis de actitudes y prácticas, como la gratuidad, la receptividad, la contemplación, el respeto, la paciencia, la temura, etc. que, aparentemente, son muy poco constructoras.

El cristianismo mesiánico de mañana estará en condiciones de percibir que la construcción de la salvación en la historia es, al mismo tiempo, fruto de la gratuidad y del mandato. Buscar una justicia siempre mayor será para él una exigencia absoluta de la fe. Pero ojalá haya podido aprender a tiempo que nada hay más demandante de justicia para los demás que la experiencia de la gratuidad del amor de Dios, que abre en nosotros posibilidades históricas a lo imposible: ser filialmente fiel y fratemalmente solidario. Si la lucha por la justicia la mantiene como ley, tarde o temprano, la constatación de su imposibilidad le desmovilizará.

En cambio, si la acoge como gracia, percibirá sus constantes dinamismos y reclamos en la experiencia del "amor de Dios que inunda nuestros corazones por el Espíritu Santo que se nos ha dado" (cfr. Rom 5, 5). Entonces, el cristianismo 
mesiánico se sabrá, ante todo, agraciado y remitido constantemente a ese don, en su tarea histórica, y no "encadenado" a un imperativo categórico. Libre del cauti"verio de las obras y la ley, purificará la práctica de la justicia de su propia "hybris": la ilusoria absolutización del propio proyecto, que termina por convertirlo, inexorablemente, en camino de destrucción y de muerte. En todo tiempo, cualquier proyecto histórico de lucha por la justicia será incapaz de alcanzar una justicia plena para todas las víctimas de la miseria del mundo. Más aún, le resultará inevitable pagar su propia cuota a la injusticia, pues ninguna obra humana es capaz de traer consigo una justicia químicamente pura. Sólo la misericordia de Dios y su poder de resucitar muertos purificará la obra de nuestras manos y hará justicia definitiva a las víctimas de la historia. 